\title{
Numerical Analysis of the Combustion Characteristics for the Power Improvement and Additional SOFA System in a Pulverized-Coal Boiler
}

\author{
Yu Jiang ${ }^{1}$, Seok-Gi Ahn ${ }^{1}$, Dong-Hun $\mathrm{Oh}^{2}$, Chung-Hwan Jeon ${ }^{1}$ \\ ${ }^{1}$ School of Mechanical Engineering, Pusan National University \\ Busandaehak-ro 63beon-gil, Geumjeong-gu, Busan, Republic Of Korea \\ jxy512@hotmail.com; seokgi0502@naver.com; chjeon@ pusan.ac.kr \\ ${ }^{2} 160$, Boryeongbuk-ro, Boryeong-si, Chungcheongnam-do, Republic Of Korea \\ odh468@komipo.co.kr
}

\section{Extended Abstract}

Tangentially fired pulverized coal boilers are one of the most widely used boilers in power plants because of their good flame distribution and uniform wall heat flux to the furnace walls and have been used to generate power in Korea[1].In this study, numerical investigation on the power improvement and air staging technology in a 500MWe tangentially fired pulverized-coal boiler has been performed to understand the effect of the characteristics of the combustion, temperature, NOx emission and unburnt carbon residual. The pulverized-coal boiler is simulated within CFD models implemented in the ANSYS FLUENT V17.1 software and the fluid flow and coal particle combustion process are modeled using the Euler-Lagrange approach. The governing equations for the conservations of energy, mass, momentum, and species are solved[2].The boiler was designed to burn low-rank coal (5,600 kcal $/ \mathrm{kg})$. And the existing 500MWe PC (Pulverized Coal) boiler reduces the NOx production by multi-stage combustion of OFA (Over Fire Air) and PM (Pollution Minimum) burner[3-4]. However, as domestic NOx emission standards become more stringent, additional NOx reduction technologies are needed. Here, the traditional air staging technology has been unable to meet the reduction of pollutants, so we append the SOFA (Separated Over-Fire Air) system, this can be a good way to reduce the NOx generation[5]. So we introduce the concept of that SOFA (Separated Over-Fire Air) system with a pulverized-coal boiler. The CFD analysis represents a useful technology to provide the flow and temperature fields. And we expect this emission control technologies to reduce environmental pollution and the impact on human health.

\section{References}

[1] J. Fan, L. Qian, Y. Ma, P. Sun, K. Cen, "Computational modeling of pulverized coal combustion processes in tangentially fired furnaces," Chem Eng J, vol. 81, pp. 261-269, 2001.

[2] ANSYS, “ANSYS FLUENT Theory Guide, Release 17.1”, 2016.

[3] C. R. Choi, C. N. Kim, "Numerical investigation on the flow, combustion and NOx emission characteristics in a 500 MWe tangentially fired pulverized-coal boiler," Fuel, vol. 88, pp. 1720-1731, 2009.

[4] M. Chernetskiy, A. Dekterev, N. Chernetskaya, K. Hanjalić, "Effects of reburning mechanically-activated micronized coal on reduction of NOx: Computational study of a real-scale tangentially-fired boiler," Fuel, vol. 214, pp. 215-229, 2018.

[5] D. Li, X. Liu, Y. Feng, C. Wang, Q. Lv, Q. Zha, J. Zhong, D. Che, "Effects of oxidant distribution mode and burner configuration on oxy-fuel combustion characteristics in a 600 MWe utility boiler," Applied Thermal Engineering, vol. 124, pp. 781-794, 2017. 